\title{
Oxidative stress in Alzheimer disease as a target for therapy
}

\author{
Pohanka M \\ Faculty of Military Health Sciences, University of Defense, Hradec Kralove, Czech Republic. \\ miroslav.pohanka@gmail.com
}

\begin{abstract}
In the recent time, neurodegenerative disorders like Alzheimer disease were recognized for their significant role in the current healthcare because of their growing incidence and costs for health insurance systems. Effective therapy is missing and even etiology of the diseases like Alzheimer disease is not deeply known. In the case of Alzheimer disease, it is probable that oxidative stress is at least a factor involved in the disease. Nevertheless, the current literature is controversial and ambiguous in this matter. This review is focused on mapping the role of oxidative stress as well as on a consideration that oxidative stress represents the pathway at which a therapeutic strategy can be aimed. This paper provides a survey of contemporary literature on oxidative stress in Alzheimer disease and discusses the opportunities for establishing a therapy based on interfering the stress (Fig. 5, Ref. 117). Text in PDF www.elis.sk.

KEY WORDS: Alzheimer disease, amyloid plaque, oxidative stress, Fenton reaction, neurodegenerative disorder, reactive oxygen species.
\end{abstract}

\section{Introduction}

Alzheimer (or Alzheimer's in some sources) disease is a neurodegenerative disorder which is an object of an extensive research. The disease is known for its recent high incidence while the probability of its manifestation is higher in elder people. The incidence can reach $20 \%$ for those at age above 90 years $(1,2)$. In a European study, an incidence of $7.2 \%$ was proved for population older than 65 years (3). When developed, the disease can be recognized by typical hallmarks like decline of short-term memory, problems with visuospatial perception, and impairment in language and executive functioning (4). Alzheimer disease can be simply diagnosed using just the fact that cognitive functions are declined. While being a cheap alternative to the expensive laboratory tests based on biochemical markers, the Mini-Mental Status Exam known as a MMSE test serves for this purpose and is considered to be a first-choice tool in many healthcare systems. Despite its simplicity, the MMSE test is a reliable tool helping to recognize the disease in its early stage (5).

This review is focused on mapping the role of oxidative stress as well as on a consideration that oxidative stress represents the pathway at which the effects of therapeutic strategies can be targeted. Oxidative stress is a pathology producing reactive oxygen or nitrogen species to an extent that the body is no longer able to scavenge them. The association between Alzheimer disease

Faculty of Military Health Sciences, University of Defense, Hradec Kralove, Czech Republic

Address for correspondence: M. Pohanka, Faculty of Military Health Sciences, University of Defense, Trebesska 1575, CZ-500 01 Hradec Kralove, Czech Republic.

Phone: +420973253028 and oxidative stress is widely investigated and it appears to be a potential target of therapy (6-8). The paper provides a survey of contemporary literature on oxidative stress in Alzheimer disease and discusses the wide consequences of intervening with therapy focused on these pathways.

\section{Current therapy and the major pathological processes relat-} ed to Alzheimer disease

Many theories about pathological processes can be learned from literature including genetics which can play a role in some types of familiar and early-onset degenerative disorders of Alzheimer type (9-11) and be a link between immunity and the disease $(12,13)$. When searching the molecular processes related to Alzheimer disease, two dominant pathological hallmarks were identified. The formation of amyloid plaques can be mentioned as being the first of the hallmarks, while the development of neurofibrillary tangles is the second one.

Amyloid plaques are formed by an amyloid $\beta$ peptide, Abeta 42 , while number 42 gives the count of amino acids in its chain. Short amyloid chains come from hydrolysis of amyloid precursor protein and a huge number of amyloids differing in their length are formed by activity of $\alpha$ secretase, $\beta$ secretase or $\gamma$ secretase (14). The amyloid precursor protein has probably multiple functions in cells including excitability by outer signals, while its role in memory and olfactory function is also discussed in the current literature (15-17). In the hydrolysis of the amyloid precursor protein, the reaction starts by an action of either $\alpha$ secretase or $\beta$ secretase. The second step is mediated by $\gamma$ secretase which contains substantial parts known as presenilin (18) and it is the presenilin which is suspected to be the cause of amyloid plaques formation because presenilin genes are frequently mutated in pa- 
tients with manifested Alzheimer disease (19). The most reactive form of amyloid peptides, Abeta 42, is formed by a consequent action mediated with $\beta$ and $\gamma$ secretases (20). The other forms of amyloid $\beta$ peptides can arise by hydrolysis while various lengths, typically from 36 to 43 , can be expected (21). Chemical properties of Abeta 42 are founded on the presence of methionine in position 35. Methionine is probably responsible for the detrimental properties of Abeta 42 because of the generation of reactive oxygen species, involvement in polymerization of amyloid plaques and heavy metals complexation (22). The displacement of methionine by mutagenesis consequently alters the chemical properties including the generation of reactive oxygen species $(23,24)$. The heavy metals bound into formed amyloids can further initiate generation of reactive oxygen species by Fenton reactions (25-27). -

Tau protein is another macromolecule tightly linked to Alzheimer disease development. The protein is known for its structural function which consists of stabilizing the N-terminal part of microtubules dominantly in neuronal axons, glia and astrocytes (28-30). Under normal conditions, tau protein is phosphorylated by calcium-calmodulin-dependent protein kinase II, casein kinases, glycogen synthase kinase $3 \beta$, cyclin dependent kinases cdc 2 and cdk5, stress activated kinases and others (31-33). The reverse process, dephosphorylation, is mediated by PP1, PP2A, PP2B and PP5 phosphatases $(34,35)$. The processes of both, phosphorylation and dephosphorylation are not well understood and the mechanism of phosphorylation regulation is also unknown (36). Under some conditions which are not fully understood, hyperphosphorylation can be started. The hyperphosphorylation of tau protein takes place in pathologies commonly called tauopathies. Amyotrophic lateral sclerosis, corticobasal degeneration, dementia pugilistica, and fronto-temporal dementia can be introduced as tauopathies beside Alzheimer disease where hyperphosphorylation of tau protein also occurs (37-41). Tauopathy can be also revealed in Parkinson disease patients (42).

The question as to why tau proteins become hyperphosphorylated remains unanswered. Malfunction of mitochondrial metabolism $(43,44)$, catalysis by Abeta $42(45)$ as well as catalysis of some metals like aluminum (46) and glucose-related metabolic disorders like diabetes (47) can be mentioned as suspected factors for the initiation of hyperphosphorylation.

Surprisingly, none of the current drugs used in Alzheimer disease therapy is purposefully focused on interfering in the amyloid deposition or hyperphosphorylated tau formation. Two major current strategies are common, namely the inhibition of acetylcholinesterase (AChE) and antagonism on the N-methyl-D-aspartate receptor (NMDAR). The strategies improve cognitive abilities and ameliorate Alzheimer disease manifestation, but the therapy is not a causative one. The currently available drugs include rivastigmine, a pseudo-irreversible inhibitor of AChE and butyrylcholinesterase, a competitive inhibitor of $\mathrm{AChE}$ galantamine, and non-competitive inhibitor of AChE, as well as memantine, a substance blocking NMDA receptors (48-51). Chemical structures of the latter drugs are depicted in Figure 1.

Other strategies are investigated but they have not yet passed through clinical trials successfully or been commercialized for a
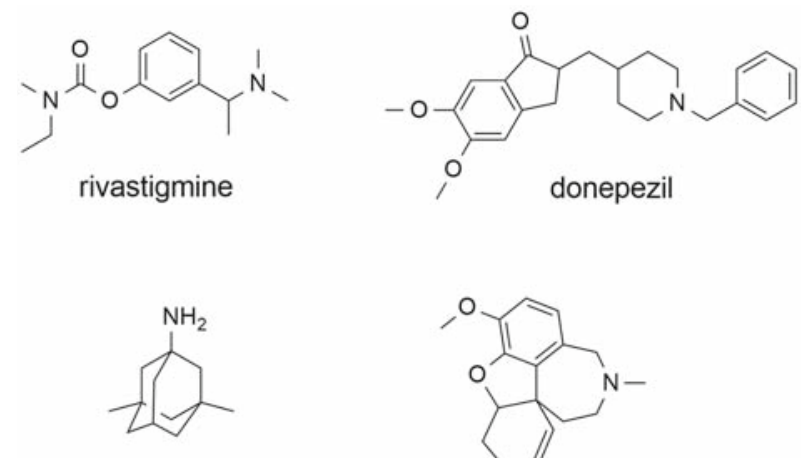

memantine

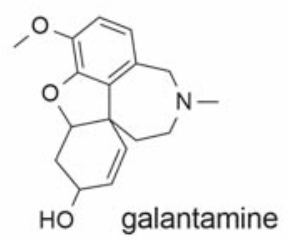

Fig. 1. Chemical structures of AChE inhibitors galantamine, rivastigmine and donepezil, and NMDAR antagonist memantine which are used in Alzheimer disease therapy.

general use. New types of cholinesterase inhibitors can be pointed out of which huperzine and its ZT-1 derivative can be introduced as drugs on a common principle $(52,53)$ whereas other approaches like vaccination against tau and amyloid beta $(54,55)$ or synthesis of new $\beta$ secretase inhibitors $(56,57)$ are other ways of pharmacologic treatments.

\section{Global view on oxidative stress in the Alzheimer disease}

The theories that oxidative stress causes Alzheimer disease are not unified in their explanation of the processes leading to the disease. There is uncertainty in assessing the significance of stress, distinguishing between the cause and consequences, or even in defining the role of reactive compound as an only marker. Currently, there are some antagonistic theories and hypotheses to be learned while it is fair to mention even the extreme ones. The oxidative stress is not fully accepted by all researchers as a physiologically significant process and this approach to oxidative stress can be mentioned as one end of the opinion spectrum. On the other end, there is of course the full acceptation of the role of oxidative stress and recognizing it as the causative pathological process in many diseases including Alzheimer disease as well as the major or even only one factor initiating the disease. Compromising theories and hypotheses are laid up between the two extremes. Oxidative stress then can be designated as a co-factor necessary for the development of Alzheimer disease, factor worsening the progression but not necessarily initiating the disease while in its mildest variant, oxidative stress is considered to be an only marker albeit without causative effect. The last theory can be abbreviated as smoke (oxidative stress) over fire (other pathological process) and can be generalized for all pathologies with oxidative stress playing a role. This idea was widely discussed by some researchers in their works (58). Regarding Alzheimer disease, the role of oxidative stress cannot be simply evaluated because the etiology of this disease has not been revealed yet (59-61). In this work, oxidative stress is assumed to be a factor supporting the pathologic process 
and the interference in oxidative stress a way of ameliorating the pathological consequences.

Currently, oxidative stress in patients suffering from Alzheimer disease is expected to be initiated by one or more sources. Namely, the roles of amyloid plaques, heavy metals, and malfunctioned metabolism in mitochondria are the most accepted theories. Other pathways can be also involved in other theories and hypotheses occurring in current literature.

\section{Amyloids and oxidative stress}

As mentioned previously, amyloid plaques are probably associated with oxidative stress formation and more independent pathways of reactive oxygen species formation are even involved in stress development. Methionine in position 35 of Abeta 42 plays a substantial role in the production of reactive oxygen species and depletion of low molecular weight antioxidants as indicated is some works (62). The role of methionine 35 is caused by a chemical process allowing to oxidize the sulphur moiety by various oxidizing agents like reactive oxygen species giving rise to methionine sulfoxide. The reduction of methionine sulfoxide is mediated by enzymes like methionine sulfoxide reductase. The methionine sulfoxide can be further oxidized up to methionine sulfone. The oxidation of methionine and reduction of methionine sulfoxide is depicted in Figure 2. Methionine sulfoxide reductase is responsible for the turning of oxidized methionine containing sulfoxide group back to its reduced form and it is indicated that this pathway is a promising target for therapy protecting from amyloid plaques formation (63). In some works, oxidative status of methionine 35 is shown to correlate with reduced risk for amyloid plaque formation and ameliorate the development of oxidative stress (64). In other works, cytotoxicity of sulfoxide containing Abeta 42 is proved (65). On the other hand, other papers are concluded by a statement that the oxidative status of methionine does not play a significant role in the plaques formation and further catalytical production of reactive oxygen species (66). Understanding the role of methionine 35 needs more experiments and both, chemical properties of pure Abeta 42 and its interactions with other structures in the cells need to be better clarified. As discussed further, amyloids are potent chelators for heavy metals which can also contribute to oxidative stress.

\section{Metabolism as a source of reactive compounds}

Basic metabolism is also a possible source of reactive oxygen species and a contributor to the development of Alzheimer disease. The question of the role of metabolism in antioxidant homeostasis and even in the Alzheimer disease is a little complicated because of the huge scale of basic metabolism. For instance, working-age population daily consumes food typically worth of $1500-3500$ $\mathrm{kcal}$ per $(6276-14644 \mathrm{~kJ}$ per a day). But the wider spectrum is real because of high or no physical activity, diseases, diets, gender, lactation, in elderly or young people (67-71). People need oxygen for their metabolic function as an inevitable part of oxidative phosphorylation and the consumption of energy is tightly connected with breathing in the oxygen. From the taken oxygen, approximately $1 \%$ is transmitted to reactive oxygen species like hydrogen peroxide rather than to harmless compounds like water (72). This fact is mentioned for understanding the amount of reactive oxygen species produced by basal metabolism. The reactive compounds are of course produced by other pathways as well. Various oxygenases like cytochrome P450 $(73,74)$, production of reactive compounds like nitric oxide by nitric oxide synthase in cellular signaling and others $(27,75,76)$, and complex IV of mitochondrial respiratory chain creating hydrogen peroxide rather than water (77-79) take place in reactive oxygen and nitrogen species production under physiological conditions. The production of reactive compounds can be increased under pathological conditions. For instance hypoxia significantly increases the production (80).

Nitric oxide represents a specific reactive compound having a role in Alzheimer disease. During investigation of Alzheimer disease, hypertension was identified to be a risk factor accelerating the disease progression (81) while the increased activity of nitric oxide synthase followed by a release of nitric oxide is typical for this type of pathology $(82,83)$. Nitric oxide is created by nitric oxide synthase from NADPH, oxygen molecule, and L-arginine. Citrulline, nitric oxide, water and $\mathrm{NADP}^{+}$are products from the reaction. Nitric oxide is not a reactive compound itself, but it chemically reacts with superoxide anion providing peroxinitrite. The mentioned chemical reactions are presented in Figure 3. The superoxide itself can be formed in various ways from which the reaction mediated by NADPH oxidase appears as a relevant one

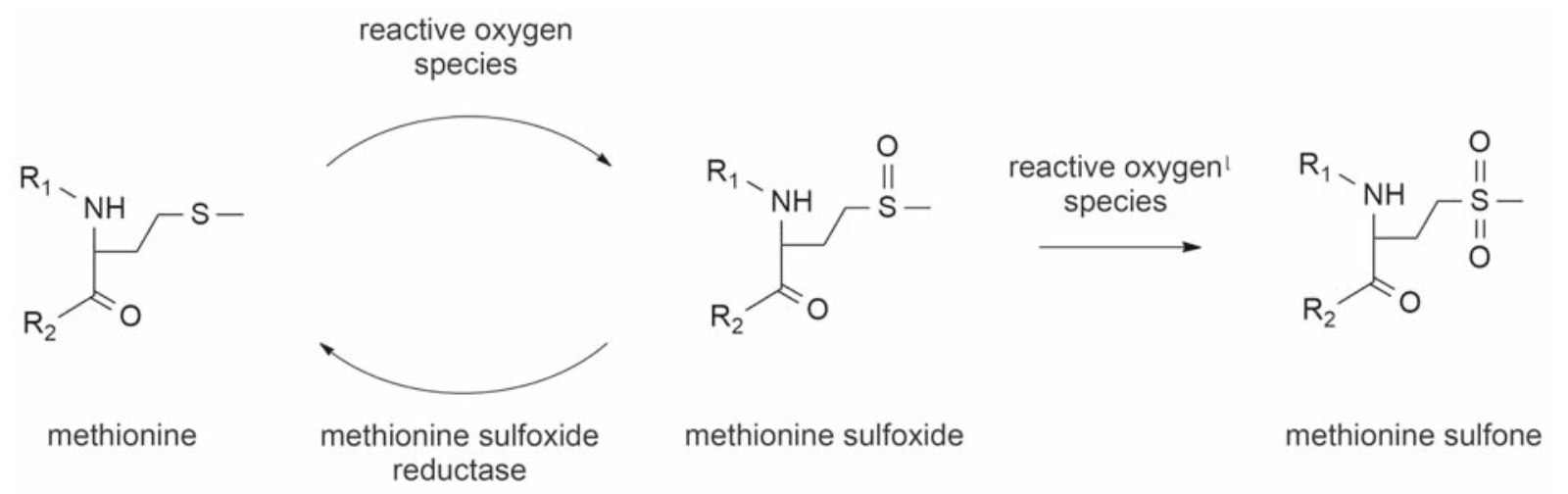

Fig. 2. Oxidation of methionine and reduction of methionine sulfoxide by methionine sulfoxide reductase. 
Production of nitric oxide by nitric oxide synthase:

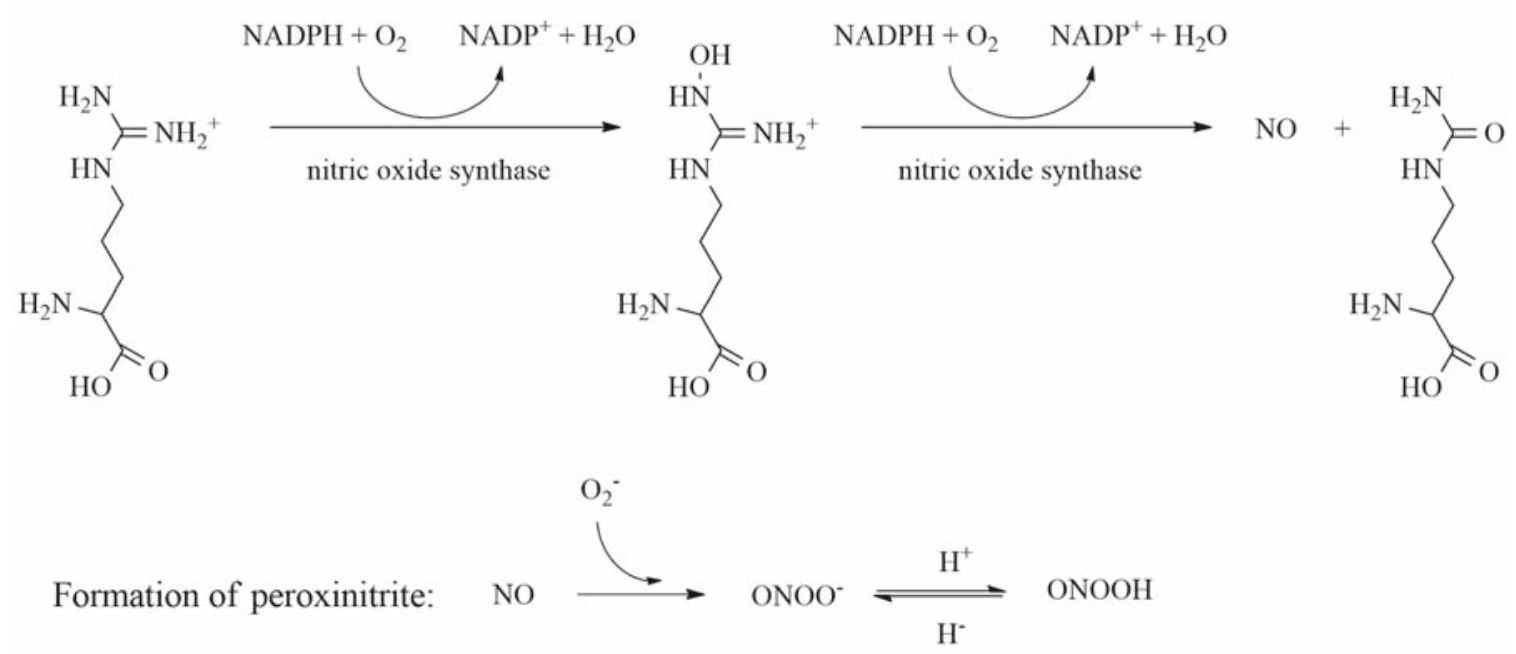

Fig. 3. Chemical reactions leading to formation of nitric oxide by catalysis of nitric oxide synthase and formation of peroxinitrite by a reaction between nitric oxide and superoxide anion.

normal function

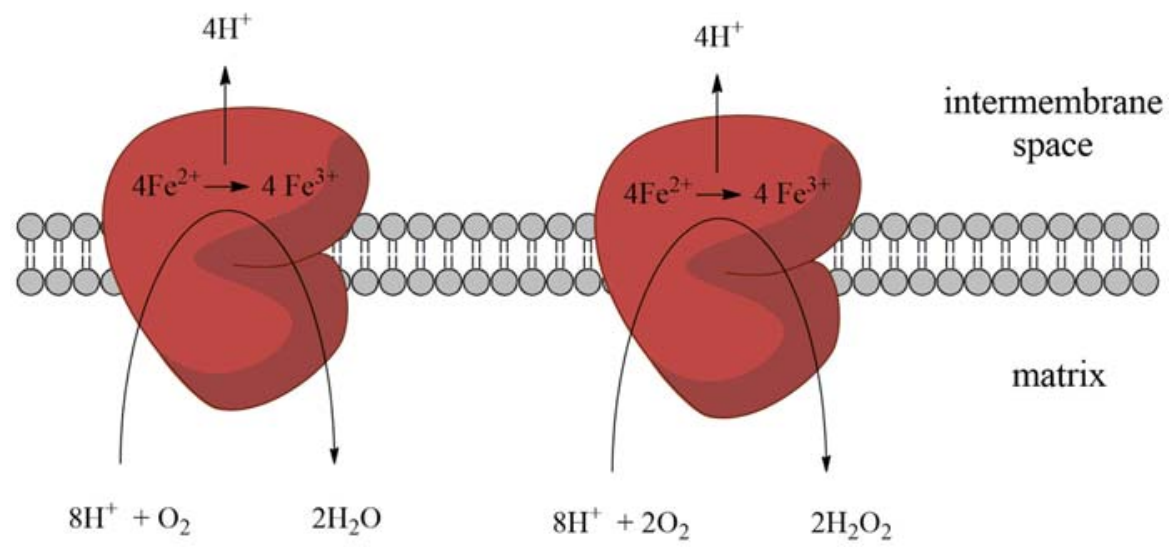

Fig. 4. Graphic presentation of chemical reaction mediated by complex IV of mitochondrial respiratory chain under normal and impaired functions

while the association between NADPH oxidase expression and neuropathologies including Alzheimer disease is also deeply investigated $(84,85)$. The peroxinitrite is a cytotoxic compound given to a wider group of reactive oxygen and nitrogen species and a significant contributor to oxidative stress (86-88). Considering the mentioned facts, nitric oxide would appear as a compound inducing oxidative stress in patients suffering from Alzheimer disease; however, the situation is not too close to the conclusion. Studies on transgenic mice serving as the disease model exerted higher pathological findings and more intense phosphorylation of tau was present when the mice were not able to express the endothelial type of nitric oxide synthase (89). Similar findings are presented elsewhere (90). Although it is premature to make a simple recom- mendation because the studies are on model organisms and further research on patients is necessary, it is highly probable that reactive oxygen species can be indicated as a target for therapy while reactive nitrogen species should be excluded from therapy targeting. When developing new drugs, the probably different roles of reactive oxygen and nitrogen species in the disease should be taken into consideration. Simple administration of low-molecular weight antioxidants or preparation of drugs with antioxidant potency will probably have a limited therapeutic impact because two pathways with negative reactive oxygen species and none, or positive reactive nitrogen species become interfered.

Normal and impaired functions of complex IV of mitochondrial respiratory chain were chosen as an example (depicted in 
Figure 4) of a significant metabolic pathway causing the production of either a harmless compound (water) or harmful hydrogen peroxide. Considering the aforementioned facts, it is not surprising that mitochondria, the most metabolically active compartments of a cell, are significant producers or reactive oxygen species (91). The mitochondria can be also injured by the produced reactive compounds, and apoptosis of the whole cell can get started. When reactive oxygen species damage the mitochondria, it is going to have consequences for the whole cell because apoptosis can be started (92). The role of mitochondria in Alzheimer disease is considered to be one of the crucial factors and oxidative stress probably represents a link to an essential role $(93,94)$. Since the start of the Alzheimer disease research, many theories regarding mitochondria have been stated. Both opinions, namely the one that mitochondria are injured by Alzheimer pathology (presence of amyloid plaques or neurofibrillary tangles) and become impaired which worsens the disease, and the second one assume that the etiology of the disease lies in mitochondria and the impairment of mitochondria or excessive production of reactive compounds is a step preceding the formation of amyloid plaques and neurofibrillary tangles. A suspicion that mitochondria can take a role in Alzheimer disease is also supported by the fact that $\gamma$ secretase exerts high activity in the membranes of the rough endoplasmic reticulum just close to mitochondria (95-97), hence the impairment in mitochondrial metabolism can easily reach the sites where amyloid plaques are formed. Some studies confirmed that mitochondrial metabolism is altered because of hyperphoshporylated tau (98-100) or amyloid plaques (101-104) in the proximity of mitochondria.

\section{Metals as a player in Alzheimer disease and their contribu- tion to oxidative stress}

Amyloid plaques are a site where metal ions can be captured while it is known that aluminum, copper, iron and zinc interact with amyloid proteins (105-107). Just aluminum was identified as a causative agent of Alzheimer disease in early works (108-112). The theory was neglected in the further periods of research, though the possibility that aluminum contributes to the disease in some way is still considered by some researchers at least as a relevant co-factor (113). It has to be also stated that aluminum is a causative agent of pathologies resembling Alzheimer disease in their manifestation. Neurotoxicity of aluminum deposition in nervous system is also a proven fact that supports theories claiming that there is a link (114).

Deposition of metals or metallic ions in amyloid plaques can easily cause overproduction of reactive oxygen species and development of oxidative stress inside cells when the reactive species generation is uncovered by an antioxidant defense system. The metals can cause a wide number of pathologic consequences of stabilizing the amyloid plaques by chemical reactions with free thiols on proteins etc. Inflammatory reaction, more precisely neuroinflammation in sites of metals like copper deposition can be expected (115). The inflammatory processes are followed by systematic production of reactive compounds by microglia and other immunity cells $(27,116,117)$. The role of immunity in Alzheimer
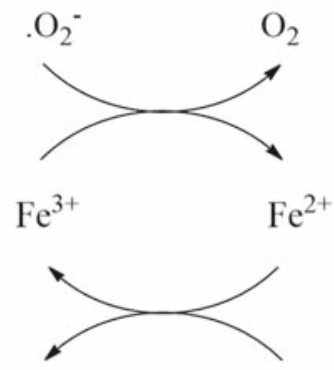

$\mathrm{HO}^{-}+\mathrm{HO} \quad \mathrm{H}_{2} \mathrm{O}_{2}$

Fig. 5. Fenton reaction and Haber Weiss reaction catalyzed by iron.

disease and the possible link between immunity and oxidative stress accent the fact that more factors contribute to the final pathology. Regarding Alzheimer disease, Fenton reaction appears to be a significant pathway possibly leading to the production of cytotoxic reactive oxygen species. The Fenton reaction is caused by some metals that can alter their oxidation state which are the both non-biogenic metals like cadmium and biogenic ones like copper and iron (27). Redox changes of $\mathrm{Cu}$ (I) to $\mathrm{Cu}$ (II) and $\mathrm{Fe}$ (II) to $\mathrm{Fe}(\mathrm{III})$ are common in the Fenton reaction. The Fenton reaction is connected with Haber-Weiss reaction and these two reactions provide a complete cycle, the principle of which can be learned from Figure 5. Hydrogen peroxide is a compound entering the Fenton reaction and can come from aforementioned impairment of the mitochondrial function or any other source. Metals like iron(II) or copper(I) change their oxidation states to iron(III) or copper(II) and hydrogen peroxide contemporarily splits to hydroxyl radical and hydroxide anion. Oxidized metals like iron(III) or copper(II) are reduced back just in the Haber Weiss reaction. Superoxide is a compound entering the Haber Weiss reaction while oxygen is an output. The reduction can be also mediated by low molecular weight antioxidants like ascorbic acid which is oxidized to dehydroascorbic acid. Consumption of superoxide or antioxidant and hydrogen peroxide and production of cytotoxic hydroxyl radical and relatively harmless hydroxide anion is the summary of the reaction. Interfering with pathology mediated by metal ions would be an option for therapy. Chelating the metals followed by their elimination from organism or interfering the Fenton reaction chemically would be effective ways for introducing a new therapy for Alzheimer disease.

\section{Conclusions}

In the current time, there is no causative therapy for Alzheimer disease. It is not surprising because its etiology has not been yet revealed while the effort of developing an effective therapy without understanding the wider details its impact is like taking a shot in the dark. Oxidative stress is a pathology where reactive oxygen or nitrogen species are produced and the organism is not able to scavenge them by antioxidants or in any other way. As such it appears to be at least a contributor to pathological pro- 
cesses taking place in the nervous system of patients suffering from Alzheimer disease. Interfering with the production of reactive oxygen species would be a promising strategy for alleviating the disease consequences. When compared to the scavenging of reactive oxygen species, , the therapy based on the scavenging of reactive nitrogen species is questionable because of the biological role of nitric oxide and risks arising from interfering with this pathway. Nevertheless, a complex research on Alzheimer disease is necessary prior to making an unambiguous conclusion. Regarding the oxidative stress interference, the situation is complicated because reactive species can be probably produced by means of more than one pathway associated to Alzheimer disease. Studies on the pathways is more than necessary in bringing new compounds with antioxidant properties.

\section{References}

1. Kukull WA, Higdon R, Bowen JD et al. Dementia and Alzheimer disease incidence: A prospective cohort study. Arch Neurol 2002; 59 (11): $1737-1746$.

2. Lobo A, Lopez-Anton R, Santabarbara J et al. Incidence and lifetime risk of dementia and Alzheimer's disease in a southern european population. Acta Psychiatr Scand 2011; 124 (5): 372-383.

3. Dimitrov I, Tzourio C, Milanov I, Deleva N, Traykov L. Prevalence of dementia and mild cognitive impairment in a bulgarian urban population. Am J Alzheimers Dis Other Demen 2012; 27 (2): 131-135.

4. Crane PK, Trittschuh E, Mukherjee S et al. Incidence of cognitively defined late-onset Alzheimer's dementia subgroups from a prospective cohort study. Alzheimers Dement 2017; 15 (17): 30216-30219.

5. Collignon J, Rouch I, Gonthier R et al. Refusal of application to care in Alzheimer's disease and related diseases: Establishment of a mobile unit hospital extra. Geriatr Psychol Neuropsychiatr Vieil 2013; 11 (1): 49-55.

6. Pohanka M. Alzheimer's disease and oxidative stress. A review. Curr Med Chem 2014; 21 (3): 356-364.

7. Poprac P, Jomova K, Simunkova M, Kollar V, Rhodes CJ, Valko M. Targeting free radicals in oxidative stress-related human diseases. Trends Pharmacol Sci 2017; 38 (7): 592-607.

8. Ortiz GG, Pacheco Moises FP, Mireles-Ramirez M et al. Oxidative stress: Love and hate history in central nervous system. Adv Protein Chem Struct Biol 2017; 108: 1-31.

9. Wang JC, Alinaghi S, Tafakhori A et al. Genetic screening in two iranian families with early-onset Alzheimer's disease identified a novel psen1 mutation. Neurobiol Aging 2017; 23 (17): 30350-30350.

10. Verheijen J, van der Zee J, Gijselinck I et al. Common and rare tbk1 variants in early-onset Alzheimer disease in a european cohort. Neurobiol Aging 2017; 25 (17): 30351-30352.

11. Shea YF, Chu LW, Lee SC, Chan AO. The first case series of chinese patients in hong kong with familial Alzheimer's disease compared with those with biomarker-confirmed sporadic late-onset Alzheimer's disease. Hong Kong Med J 2017; 10 (10).

12. Morgan BP. Complement in the pathogenesis of Alzheimer's disease. Semin Immunopathol 2017; 13 (10): 017-0662.

13. Takada LT. Innate immunity and inflammation in Alzheimer s disease pathogenesis. Arq Neuropsiquiatr 2017; 75 (9): 607-608.
14. Ortega F, Stott J, Visser SA, Bendtsen C. Interplay between $\alpha$-, $\beta$, and $\gamma$-secretases determines biphasic amyloid- $\beta$ protein level in the presence of a $\gamma$-secretase inhibitor. J Biol Chem 2013; 288 (2): 785-792.

15. Korte M, Herrmann U, Zhang X, Drguhn A. The role of app and aplp for synaptic transmission, plasticity, and network function: Lessons from genetic mouse models. Exp Brain Res 2012; 217 (3-4): 435-440.

16. Turner PR, O'Connor K, Tate WP, Abraham WC. Roles of amyloid precursor protein and its fragments in regulating neural activity, plasticity and memory. Prog Neurobiol 2003; 70 (1): 1-32.

17. Kim JY, Rasheed A, Yoo SJ et al. Distinct amyloid precursor protein processing machineries of the olfactory system. Biochem Biophys Res Commun 2017; 31 (17): 32138-32131.

18. Dolev I, Fogel H, Milshtein H et al. Spike bursts increase amyloid- $\beta$ $40 / 42$ ratio by inducing a presenilin-1 conformational change. Nat Neurosci 2013; doi: 10.1038/nn.3376.

19. Jankowsky JL, Fadale DJ, Anderson J et al. Mutant presenilins specifically elevate the levels of the 42 residue beta-amyloid peptide in vivo: Evidence for augmentation of a 42 -specific gamma secretase. Hum Mol Genet 2004; 13 (2): 159-170.

20. Robertson AS, Iben LG, Wei C et al. Synergistic inhibition of abeta production by combinations of gamma-secretase modulators. Eur J Pharmacol 2017; 812: 104-112.

21. Kakuda N, Miyasaka T, Iwasaki N et al. Distinct deposition of amyloid-beta species in brains with Alzheimer's disease pathology visualized with maldi imaging mass spectrometry. Acta Neuropathol Commun 2017; 5 (1): 017-0477.

22. Sultana R, Robinson RA, Lange MB et al. Do proteomics analyses provide insights into reduced oxidative stress in the brain of an Alzheimer disease transgenic mouse model with an m6311 amyloid precursor protein substitution and thereby the importance of amyloid-beta-resident methionine 35 in Alzheimer disease pathogenesis? Antioxid Redox Signal 2012; 17 (11): 1507-1514.

23. Hou L, Lee HG, Han F et al. Modification of amyloid-beta1-42 fibril structure by methionine-35 oxidation. J Alzheimers Dis 2013; 37 (1): 9-18.

24. Butterfield DA, Galvan V, Lange MB et al. In vivo oxidative stress in brain of Alzheimer disease transgenic mice: Requirement for methionine 35 in amyloid beta-peptide of app. Free Radic Biol Med 2010; 48 (1): 136-144.

25. Tougu V, Tiiman A, Palumaa P. Interactions of zn(ii) and cu(ii) ions with Alzheimer's amyloid-beta peptide. Metal ion binding, contribution to fibrillization and toxicity. Metallomics 2011; 3 (3): 250-261.

26. Hane F, Tran G, Attwood SJ, Leonenko Z. Cu(2+) affects amyloid- $\beta$ (1-42) aggregation by increasing peptide-peptide binding forces. PLoS One 2013; 8 (3): e59005.

27. Pohanka M. Role of oxidative stress in infectious diseases. A review. . Folia Microbiol 2013; 58 (6): 503-513.

28. Zhang G, Beati H, Nilsson J, Wodarz A. The drosophila microtubule-associated protein mars stabilizes mitotic spindles by crosslinking microtubules through its n-terminal region. PLoS One 2013; 8 (4): e60596.

29. Brandt R, Hundelt M, Shahani N. Tau alteration and neuronal degeneration in tauopathies: Mechanisms and models. Biochim Biophys Acta 2005; 1739 (2-3): 331-354.

30. Ferrer I, Lopez-Gonzalez I, Carmona $M$ et al. Glial and neuronal tau pathology in tauopathies: Characterization of disease-specific phenotypes and tau pathology progression. J Neuropathol Exp Neurol 2014; 73 (1): 81-97. 
31. Keenev JT, Swomley AM, Harris JL et al. Cell cycle proteins in brain in mild cognitive impairment: Insights into progression to Alzheimer disease. Neurotox Res 2012; 22 (3): 220-230.

32. Lebel M, Patenaude C, Allyson J, Massicotte G, Cyr M. Dopamine d1 receptor activation induces tau phosphorylation via cdk5 and gsk3 signaling pathways. Neuropharmacology 2009; 57 (4): 392-402.

33. Boutajangout A, Sigurdsson EM, Krishnamurthy PK. Tau as a therapeutic target for Alzheimer's disease. Curr Alzheimer Res 2011; 8 (6): 666-677.

34. Liu F, Grundke-Igbal I, Igbal K, Gong CX. Contributions of protein phosphatases pp1, pp2a, pp2b and pp5 to the regulation of tau phosphorylation. Eur J Neurosci 2005; 22 (8): 1942-1950.

35. Liu F, Igbal K, Grundke-Igbal I, Rossie S, Gong CX. Dephosphorylation of tau by protein phosphatase 5: Impairment in Alzheimer's disease. J Biol Chem 2005; 280 (3): 1790-1796.

36. Tuerde D, Kimura T, Miyasaka T et al. Isoform-independent and -dependent phosphorylation of microtubule-associated protein tau in mouse brain during postnatal development. J Biol Chem 2017; 1 (798918): In press.

37. Ho WL, Leung Y, Tsang AW, So KF, Chiu K, Chang RC. Review: Tauopathy in the retina and optic nerve: Does it shadow pathological changes in the brain? Mol Vis 2012; 18: 2700-2710.

38. Ballatore C, Brundern KR, Huryn DM, Trojanowski JQ, Lee VM, Smith AB. Microtubule stabilizing agents as potential treatment for Alzheimer's disease and related neurodegenerative tauopathies. J Med Chem 2012; 55 (21): 8979-8996.

39. Cowan CM, Quraishe S, Mudher A. What is the pathological significance of tau oligomers? Biochem Soc Trans 2012; 40 (4): 693-697.

40. Huber CM, Yee C, May T, Dhanala A, Mitchell CS. Cognitive decline in preclinical Alzheimer's disease: Amyloid-beta versus tauopathy. J Alzheimers Dis 2018; 61 (1): 265-281.

41. Koss DJ, Jones G, Cranston A, Gardner H, Kanaan NM, Platt B. Soluble pre-fibrillar tau and beta-amyloid species emerge in early human Alzheimer's disease and track disease progression and cognitive decline. Acta Neuropathol 2016; 132 (6): 875-895.

42. Valli M, Strafella AP. New advances in tau imaging in parkinsonism. Int Rev Psychiatry 2017; 5: 1-8.

43. Melov S, Adlard PA, Morten K et al. Mitochondrial oxidative stress causes hyperphosphorylation of tau. PLoS One 2007; 2 (6): e536.

44. Schulz KL, Eckert A, Rhein $\mathbf{V}$ et al. A new link to mitochondrial impairment in tauopathies. Mol Neurobiol 2012; 46 (1): 205-216.

45. Yao Y, Chen X, Bao Y, Wu Y. Puerarin inhibits betaamyloid peptide 142induced tau hyperphosphorylation via the wnt/betacatenin signaling pathway. Mol Med Rep 2017; 16 (6): 9081-9085.

46. Huang W, Cheng P, Yu K, Han Y, Song M, Li Y. Hyperforin attenuates aluminum-induced abeta production and tau phosphorylation via regulating akt/gsk-3beta signaling pathway in pc12 cells. Biomed Pharmacother 2017; 96: 1-6.

47. Sun Y, Xiao Q, Luo C et al. High-glucose induces tau hyperphosphorylation through activation of tlr9-p38mapk pathway. Exp Cell Res 2017; 359 (2): 312-318.

48. Pouryamout L, Dams J, Wasem J, Dodel R, Neumann A. Economic evaluation of treatment options in patients with Alzheimer's disease: A systematic review of cost-effectiveness analyses. Drugs 2012; 72 (6): 789-802.
49. Patel L, Grossberg GT. Combination therapy for Alzheimer's disease. Drugs Aging 2011; 28 (7): 539-546.

50. Pohanka M. Cholinesterases, a target of pharmacology and toxicology. Biomed Pap Olomouc 2011; 155 (3): 219-229.

51. Pohanka M. Acetylcholinesterase inhibitors: A patent review (2008 - present). Expert Opin Ther Pat 2012; 22 (8): 871-886.

52. Jia JY, Zhao QH, Liu Y et al. Phase i study on the pharmacokinetics and tolerance of zt-1, a prodrug of huperzine a, for the treatment of Alzheimer's disease. Acta Pharmacol Sin 2013; 34 (7): 976-982.

53. Rafii MS, Walsh S, Little JT et al. A phase ii trial of huperzine a in mild to moderate Alzheimer disease. Neurology 2011; 76 (16): 1389-1394.

54. Pohanka M. Vaccination to Alzheimer disease. Is it a promising tool or a blind way? Curr Med Chem 2016; 23 (14): 1432-1441.

55. Wisniewski T, Goni F. Immunotherapeutic approaches for Alzheimer's disease. Neuron 2015; 85 (6): 1162-1176.

56. Bertini S, Ghilardi E, Asso V et al. Sulfonamido-derivatives of unsubstituted carbazoles as bace1 inhibitors. Bioorg Med Chem Lett 2017; 27 (21): 4812-4816.

57. Bertini S, Ghilardi E, Asso V et al. Bace1 inhibitory activities of enantiomerically pure, variously substituted n-(3-(4-benzhydrylpiperazin-1-yl)-2-hydroxypropyl) arylsulfonamides. Bioorg Med Chem 2010; 18 (22): 7991-7996.

58. Juranek I, Bezek S. Controversy of free radical hypothesis: Reactive oxygen species--cause or consequence of tissue injury? General physiology and biophysics 2005; 24 (3): 263-278.

59. Koncz R, Sachdev P. Are the brain's vascular and Alzheimer pathologies additive or interactive? Curr Opin Psychiatry 2017; 9 (10): 0000000000000395.

60. Solarski M, Wang H, Wille H, Schmitt-Ulms G. Somatostatin in Alzheimer's disease: A new role for an old player. Prion 2017; 1 (0): 1405207.

61. Gerakis Y, Hetz C. Emerging roles of er stress in the etiology and pathogenesis of Alzheimer's disease. Febs J 2017; 17 (10): 14332.

62. Butterfield DA, Kanski J. Methionine residue 35 is critical for the oxidative stress and neurotoxic properties of Alzheimer's amyloid betapeptide 1-42. Peptides 2002; 23 (7): 1299-1309.

63. Misiti F, Clementi ME, Giardina B. Oxidation of methionine 35 reduces toxicity of the amyloid beta-peptide(1-42) in neuroblastoma cells (imr-32) via enzyme methionine sulfoxide reductase a expression and function. Neurochem Int 2010; 56 (4): 597-602.

64. Varadarajan S, Kanski J, Aksenova M, Lauderback C, Butterfield DA. Different mechanisms of oxidative stress and neurotoxicity for Alzheimer's a beta(1--42) and a beta(25--35). J Am Chem Soc 2001; 123 (24): 5625-5631.

65. Barnham KJ, Ciccotosto GD, Tickler AK et al. Neurotoxic, redoxcompetent Alzheimer's beta-amyloid is released from lipid membrane by methionine oxidation. J Biol Chem 2003; 278 (44): 42959-42965.

66. Friedemann M, Helk E, Tiiman A, Zovo K, Palumaa P, Tougu V. Effect of methionine-35 oxidation on the aggregation of amyloid-beta peptide. Biochem Biophys Rep 2015; 3: 94-99.

67. Hurson M, Corish C. Evaluation of lifestyle, food consumption and nutrient intake patterns among irish teenagers. Ir J Med Sci 1997; 166 (4): 225-230.

68. Calloway DH, Zanni E. Energy requirements and energy expenditure of elderly men. Am J Clin Nutr 1980; 33 (10): 2088-2092. 
69. Butte NF, Wong WW, Hopkinson JM. Energy requirements of lactating women derived from doubly labeled water and milk energy output. J Nutr 2001; 131 (1): 53-58.

70. Hudson JL, Kim JE, Paddon-Jones D, Campbell WW. Within-day protein distribution does not influence body composition responses during weight loss in resistance-training adults who are overweight. Am J Clin Nutr 2017; 106 (5): 1190-1196.

71. Raty R, Carlsson-Kanyama A. Energy consumption by gender in some european countries. Energy Polic 2010; 38 (1): 646-649.

72. Klein JA, Ackerman SL. Oxidative stress, cell cycle, and neurodegeneration. J Clin Invest 2003; 111 (6): 785-793.

73. Jasinka R, Rakowska M, Lenart J, Komanska I, Pikuta S. Nonenzymatically evoked and cytochrome $\mathrm{p} 450$-dependent lipid peroxidation inhibits synthesis of phosphatidylethanolaminevia the ethanolamine base exchange reaction in rat liver microsomes. FEBS J 1996; 386 (1): 33-38.

74. Dudka J, burdan F, Korga A et al. Intensification of doxorubicinrelated oxidative stress in the heart by hypothyroidism is not related to the expression of cytochrome 450 nadph-reductase and inducible nitric oxide synthase, as well as activity of xanthine oxidase. Oxid Med Cell Longev 2012; 2012: 139327.

75. Schaue D, Kachikwu EL, McBride WH. Cytokines in radiobiological responses: A review. Radiat Res 2012; 178 (6): 505-523.

76. Niki E. Do antioxidants impair signaling by reactive oxygen species and lipid oxidation products? FEBS Lett 2012; 586 (21): 3767-3770.

77. Zigdon H, Kogot-Levin A, Park JW et al. Ablation of ceramide synthase 2 causes chronic oxidative stress due to disruption of the mitochondrial respiratory chain. J Biol Chem 2013; 288 (7): 4947-4956.

78. Kindo M, Gerelli S, Bouitbir J et al. Pressure overload-induced mild cardiac hypertrophy reduces left ventricular transmural differences in mitochondrial respiratory chain activity and increases oxidative stress. Front Physiol 2012; 3: 332.

79. Yoshikawa S, Muramoto K, Shinzawa-Itoh K. The o(2) reduction and proton pumping gate mechanism of bovine heart cytochrome $\mathrm{c}$ oxidase. Biochim Biophys Acta 2011; 1807 (10): 1279-1286.

80. Navarova J, Ujhazy E, Dubovicky M, Mach M. Phenytoin induced oxidative stress in pre- and postnatal rat development - effect of vitamin e on selective biochemical variables. Biomed Pap 2005; 149 (2): 325-328.

81. Cifuentes D, Poittevin M, Dere E et al. Hypertension accelerates the progression of Alzheimer-like pathology in a mouse model of the disease. Hypertension 2015; 65 (1): 218-224.

82. Cifuentes D, Poittevin M, Bonnin P et al. Inactivation of nitric oxide synthesis exacerbates the development of Alzheimer disease pathology in appps 1 mice (amyloid precursor protein/presenilin-1). Hypertension 2017; 31 (117): 09742.

83. Lourenco CF, Ledo A, Barbosa RM, Laranjinha J. Neurovascular uncoupling in the triple transgenic model of Alzheimer's disease: Impaired cerebral blood flow response to neuronal-derived nitric oxide signaling. Exp Neurol 2017; 291: 36-43.

84. Choi DH, Lee J. A mini-review of the nadph oxidases in vascular dementia: Correlation with noxs and risk factors for vad. Int J Mol Sci 2017; 18 (11).

85. Belarbi K, Cuvelier E, Destee A, Gressier B, Chartier-Harlin MC. Nadph oxidases in parkinson's disease: A systematic review. Mol Neurodegener 2017; 12 (1): 017-0225.
86. Aicardo A, Mastrogiovanni M, Cassina A, Radi R. Propagation of free radical reactions in concentrated protein solutions. Free Radic Res 2017; 27: 1-251.

87. Radi R. Peroxynitrite, a stealthy biological oxidant. J Biol Chem 2013; 288 (37): 26464-26472.

88. Trujillo M, Ferrer-Sueta G, Radi R. Peroxynitrite detoxification and its biologic implications. Antioxid Redox Signal 2008; 10 (9): 1607-1620.

89. Austin SA, Katusic ZS. Loss of endothelial nitric oxide synthase promotes $\mathrm{p} 25$ generation and tau phosphorylation in a murine model of Alzheimer's disease. Circ Res 2016; 119 (10): 1128-1134.

90. Roberts AM, Jagadapillai R, Vaishnav RA et al. Increased pulmonary arteriolar tone associated with lung oxidative stress and nitric oxide in a mouse model of Alzheimer's disease. Physiol Rep 2016; 4 (17): 12953.

91. Hwang AB, Jeong DE, Lee SJ. Mitochondria and organismal longevity. Curr Genomics 2012; 13 (7): 519-532.

92. Wang Y, Wu Y, Luo $\mathrm{K}$ et al. The protective effects of selenium on cadmium-induced oxidative stress and apoptosis via mitochondria pathway in mice kidney. Food Chem Toxicol 2013; doi: 10.1016/j. fct.2013.04.013.

93. Nesi G, Sestito S, Digiacomo M, Rapposelli S. Oxidative stress, mitochondrial abnormalities and proteins deposition: Multitarget approaches in Alzheimer's disease. Curr Top Med Chem 2017; 17 (27): 3062-3079.

94. Ganguly G, Chakrabarti S, Chatterjee U, Saso L. Proteinopathy, oxidative stress and mitochondrial dysfunction: Cross talk in Alzheimer's disease and parkinson's disease. Drug Des Devel Ther 2017; 11: 797-810.

95. Area-Gomez E, Del Carmen Lara Castillo M, Tambini MD et al. Upregulated function of mitochondria-associated er membranes in Alzheimer disease. EMBO J 2012; 32 (21): 4106-4123.

96. Schon EA, Area-Gomez E. Mitochondria-associated er membranes in Alzheimer disease. Mol Cell Neurosci 2013; 55: 26-36.

97. Schon EA, Area-Gomez E. Is Alzheimer's disease a disorder of mitochondria-associated membranes? J Alzheimers Dis 2010; 20 (Suppl2): S281-S292.

98. Gu XM, Huang HC, Jiang ZF. Mitochondrial dysfunction and cellular metabolic deficiency in Alzheimer's disease. Neurosci Bull 2012; 28 (5): 631-640.

99. Kiprowska MJ, Stepanova A, Todaro DR et al. Neurotoxic mechanisms by which the usp14 inhibitor iul depletes ubiquitinated proteins and tau in rat cerebral cortical neurons: Relevance to Alzheimer's disease. Biochim Biophys Acta 2017; 6 (10): 1.

100. Hu Y, Li XC, Wang ZH et al. Tau accumulation impairs mitophagy via increasing mitochondrial membrane potential and reducing mitochondrial parkin. Oncotarget 2016; 7 (14): 17356-17368.

101. Hernandez-Zimbron LF, Luna-Munoz J, Mena R et al. Amyloid- $\beta$ peptide binds to cytochrome $\mathrm{c}$ oxidase subunit 1. PLoS One 2012; 7 (8): e42344.

102. Pickrell AM, Fukui H, Moraes CT. The role of cytochrome c oxidase deficiency in ros and amyloid plaque formation. J Bioenerg Biomembr 2009; 41 (5): 453-456.

103. Nagy Z, Esiri MM, LeGris M, Matthews PM. Mitochondrial enzyme expression in the hippocampus in relation to Alzheimer-type pathology. Acta Neuropathol 1999; 97 (4): 346-354.

104. Area-Gomez E, Schon EA. Mitochondria-associated er membranes and Alzheimer disease. Curr Opin Genet Dev 2016; 38: 90-96. 
105. Wang T, Wang CY, Shan ZY, Teng WP, Wang ZY. Clioquinol reduces zinc accumulation in neuritic plaques and inhibits the amyloidogenic pathway in a $\beta p p / p s 1$ transgenic mouse brain. J Alzheimers Dis 2012; 29 (3): 549-559.

106. Bologin S, Zatta P, Lorenzetto E, Valenti MT, Buffelli M. B-amyloid-aluminum complex alters cytoskeletal stability and increases ros production in cortical neurons. Neurochem Int 2013; 62 (5): 566-574.

107. Exley C, House E, Polwart A, Esiri MM. Brain burdens of aluminum, iron, and copper and their relationships with amyloid- $\beta$ pathology in 60 human brains. J Alzheimers Dis 2012; 31 (4): 725-730.

108. Crapper DR, Krishnan SS, De Boni U, Tomko GJ. Aluminum: A possible neurotoxic agent in Alzheimer's disease. Trans Am Neurol Assoc 1975; 100: 154-156.

109. Crapper DR, Krishnan SS, Dalton AJ. Brain aluminum distribution in Alzheimer's disease and experimental neurofibrillary degeneration. Science 1973; 180 (4085): 511-513.

110. Shore D, Millson M, Holtz JL, King SW, Bridge TP, Wyatt RJ. Serum aluminum in primary degenerative dementia. Biol Psychiatry 1980; 15 (6): 971-977.
111. Delaney JF. Spinal fluid aluminum levels in patients with Alzheimer disease. Ann Neurol 1979; 5 (6): 580-581.

112. Trapp GA, Miner GD, Zimmerman RL, Mastri AR, Heston LL. Aluminum levels in brain in Alzheimer's disease. Biol Psychiatry 1978; 13 (6): 709-718.

113. Lidsky TI. Is the aluminum hypothesis dead? J Occup Environ Med 2014; 56 (5 Suppl): 0000000000000063.

114. Colomina MT, Peris-Sampedro F. Aluminum and Alzheimer's disease. Adv Neurobiol 2017; 18: 183-197.

115. Mathys ZK, White AR. Copper and Alzheimer's disease. Adv Neurobiol 2017; 18: 199-216.

116. Bagyinszky E, Giau VV, Shim K, Suk K, An SSA, Kim S. Role of inflammatory molecules in the Alzheimer's disease progression and diagnosis. J Neurol Sci 2017; 376: 242-254.

117. Asiimwe N, Yeo SG, Kim MS, Jung J, Jeong NY. Nitric oxide: Exploring the contextual link with Alzheimer's disease. Oxid Med Cell Longev 2016; 7205747 (10): 21. 